ApplicationForum

\title{
A method for preserving buccal swabs samples for gDNA integrity
}

David Navarro DanaGen-BioTed S.L, Barcelona, SPAIN david@danagen.es

Noelia S. Durán, Rebeca Álvarez Laboratorio de Medicina Molecular. Instituto de Medicina Oncológica y Molecular de Asturias (IMOMA), Oviedo, SPAIN

\section{Introduction}

The use of buccal swabs for non-invasive sample collection is well established. Samples can be stored for up to 2 weeks at $4^{\circ} \mathrm{C}$ before processing without a noticeable loss in DNA yield or quality. This storage condition is not often possible to apply immediately. If unprocessed samples are stored at room temperature, the bacteria and nucleases present in the buccal swabs will cause DNA degradation.

\section{DANAGEN-BIOTED has} developed a method using the DANASWABS Sample Collection Kit that contains a stabilizing buffer designed to completely stabilize the buccal cells from buccal swabs samples by inhibiting all enzymatic and microbial activity that occurs following any buccal sampling.

This system allows the release of the cells captured by the swab into a proprietary cell stabilizing buffer. Samples preserved with

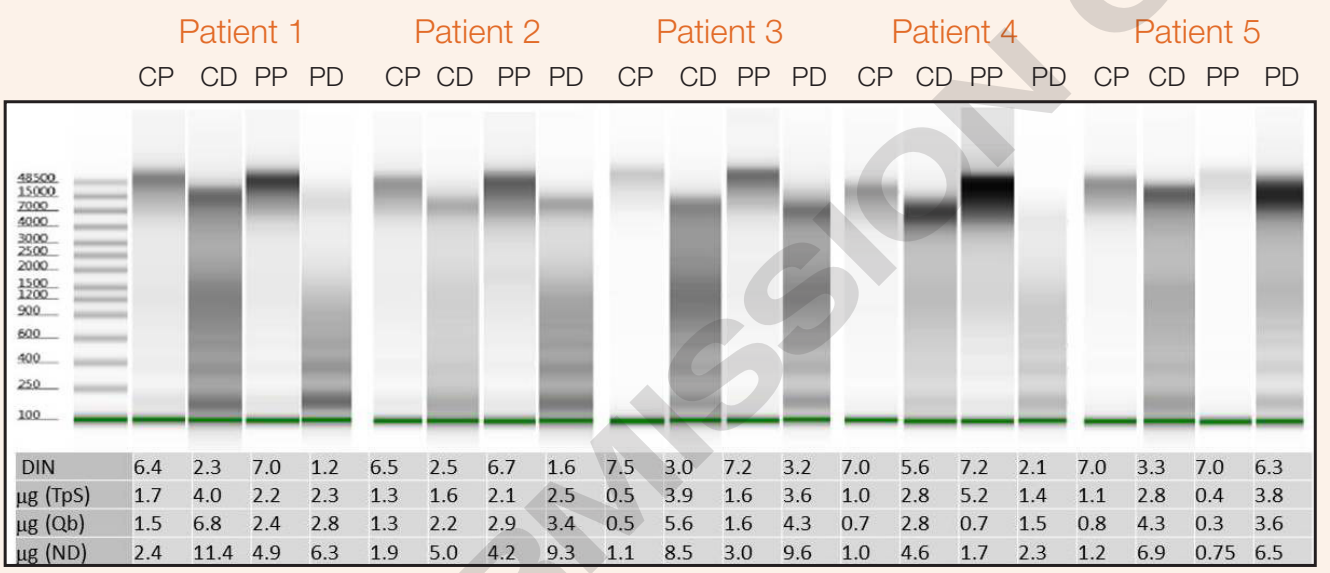

Fig. 1: CP: COPAN Swab, preserved ; CD: COPAN Swab, direct ; PP: PURITAN Swab, preserved ; PD: PURITAN swab, direct.

this system are stable for 1 year at room temperature so that they can be transported safely to the laboratory for processing.

\section{Materials \& Methods}

Buccal cells samples were collected from 5 patients using our DANASWABS Sample Collection Kit. Two swabs from different brands previously evaluated as the best performers were used (data not shown).

4 samples were taken from each patient on different days and at the same time, 2 samples were preserved with our buffer and the other 2 unpreserved (one per swab type).

3 days after sampling, the samples were processed for DNA isolation following DANAGENE Swabs DNA Kit protocol and were analyzed using the Agilent 4200 TapeStation System.

\section{Results}

DNA yield, quality and integrity were tested using the Qubit (Qb),Nanodrop (ND) and TapeStation Instrument (TpS) respectively.

\section{Conclusion}

The gel image from TapeStation and quantifications with Qubit and Nanodrop show that the DNA yield of DNA isolations performed from unpreserved swabs is higher than from swabs preserved using our system, but while the DNA of unpreserved samples is extensively degraded, preserved samples exhibit DNA integrity. The TapeStation allows to calculate the DIN, a numerical assessment of gDNA integrity referred as the DNA integrity number (DIN

Better results are also obtained with preserved samples in quantitive PCR assays (data not shown).

In this paper it is demonstrated that the buccal cells are stabilized using our DANASWABS Sample collection Kit, with the structure and integrity of the DNA being fully maintained for further downstream processing applications.

BioTechniques 61:153 (September 2016) doi 10.2144/000114455 